\title{
Effect of Stimulus Rate and Gender on Auditory Middle Latency Response in Young Adults
}

\author{
Ki-Hyeon Jang' ${ }^{1}$, Seong Hee Choi ${ }^{1,2,3}$, Chul-Hee Choi ${ }^{1,2,3}$ \\ 'Department of Audiology and Speech-Language Pathology, ${ }^{2}$ Research Institute of Biomimetic Sensory Control, \\ ${ }^{3}$ Catholic Hearing Voice Speech Center, Catholic University of Daegu, Gyeongsan, Korea
}

\begin{abstract}
Purpose: The main objective of this study was to investigate the effect of stimulus rate and gender on the latency and amplitude of the auditory middle latency response (AMLR) in Korean young females and males. Methods: A total of thirty young subjects consisting of fifteen males and fifteen females participated in the study. The stimulus repetition rate was changed in five steps: 0.5, 1, 2, 4, and 8/s. Results: The results showed significant differences of the stimulus rates on the Na latency, Pa amplitude, and Nb amplitude. With faster stimulus rates, the $\mathrm{Na}$ latency and the $\mathrm{Nb}$ amplitude slightly increased while the Pa amplitude decreased. The $\mathrm{Na}$, $\mathrm{Pa}$, and $\mathrm{Nb}$ latencies were longest with the stimulus rate of $2 / \mathrm{s}$. The $\mathrm{Na}$ and $\mathrm{Nb}$ amplitudes were largest with the stimulus rate of $4 / \mathrm{s}$ while the $\mathrm{Pb}$ amplitude was largest with the stimulus rate of $1 / \mathrm{s}$. There were significant differences in the latency of $\mathrm{Na}$ and the amplitudes of $\mathrm{Na}$, $\mathrm{Pa}, \mathrm{Nb}$, and $\mathrm{Pb}$ according to gender. The latencies of $\mathrm{Na}, \mathrm{Pa}, \mathrm{Nb}$, and $\mathrm{Pb}$ in females were longer than in males while the amplitudes of $\mathrm{Na}$, $\mathrm{Pa}, \mathrm{Nb}$, and $\mathrm{Pb}$ in males are larger than in females. Conclusion: The ranges of optimal stimulus rate to elicit the apparent AMLR waveform were $1-8 / \mathrm{s}$. This provides clinical basic data of stimulus rate and gender-specific norms on the latency and amplitude of the AMLR waveform.
\end{abstract}

Key Words: Stimulus rate, Gender, Auditory middle latency response, $\mathrm{Na} \cdot \mathrm{Pa} \cdot \mathrm{Nb} \cdot \mathrm{Pb}$.

Received: March 11, 2017 / Revised: April 13, 2017 / Accepted: April 15, 2017

Correspondence: Chul-Hee Choi, Department of Audiology and Speech-Language Pathology, Catholic University of Daegu, 13-13 Hayang-ro, Hayang-up, Gyeongsan 38430, Korea

Tel: +82-53-850-2541 / Fax: +82-53-359-0780 / E-mail: cchoi@cu.ac.kr

\section{INTRODUCTION}

After the auditory middle latency response (AMLR) had been introduced as an electrical response occurring between 10 and $100 \mathrm{~ms}$ after the introduction of an acoustical signal at a moderate intensity level, AMLR has been used a neurodiagnosis tool of cortical auditory function in children and adults with normal and abnormal hearing (Hall, 2007). In AMLR waveforms, there are four major components consisting of two negative voltage waves $(\mathrm{Na}$ and $\mathrm{Nb}$ ) and two positive voltage waves $(\mathrm{Pa}$ and $\mathrm{Pb})$. The first negative peak $(\mathrm{Na})$ occurs within $10 \mathrm{msec}$ while the prominent positive peak $(\mathrm{Pa})$ normally shows a latency of about 22-30 msec. The second negative peak ( $\mathrm{Nb}$ ) occurs in $30-40 \mathrm{msec}$ while the next positive peak $(\mathrm{Pb})$ is present in 45-50 msec (Hall, 2007). These waves of the AMLR correspond to the specific locations of the auditory cortex. The $\mathrm{Na}$ component of the AMLR arises from the inferior colliculus within the midbrain region in animals and the primary auditory cortex (Heschl's gyrus) within the temporal lobe in humans (Liegeois-Chauvel et al., 1994; McGee et al., 1991). The Pa component is generated from the subcortical and cortical regions of the auditory system while the $\mathrm{Pb}$ component has multiple origins such as the reticular activating formation and the auditory cortex, particularly the posterior region of the planum temporale (Liegeois-Chauvel et al., 1994; McGee \& Kraus, 1996; Polyakov \& Pratt, 1994).

Recently, there was some evidence for improvement of the latency and amplitude of AMLR waveforms after cochlear implantation. The AMLR has been used as a measure of the effectiveness of cochlear implantation in restoring speech perception abilities in postlingually deaf adults. The relationship between auditory evoked potentials including AMLR, mismatch negativity, and auditory late response and word/sentence speech perception after cochlear implantation was investigated in post- 
lingually deaf adults (Purdy \& Kelly, 2016). There were no consistent changes over time in AMLR and consistent changes of N1 amplitude and P2 area in auditory late response. We need to confirm the optimal stimulus parameters to reveal the closer association between auditory evoked potentials and speech perception after cochlear implantation in postlingually deaf adults.

As shown in the auditory brainstem response (ABR), the latency and amplitude of the AMLR can be affected by multiple stimulus parameters such as rate, type, duration, intensity, and polarity (Choi et al., 2015). Among these factors, the optimal stimulus rate for AMLR is clinically important because it produces quality response with minimal test time. A reliable and robust AMLR is consistently produced at the stimulus rates of $8 / \mathrm{s}$ to $11 / \mathrm{s}$. These stimulus rates are slower than those of ABR due to its relatively longer latency. However, the $\mathrm{Pa}$ component of the AMLR in infants and the Pb component of the AMLR in patients of all ages are generated by the stimulus rates of $1 / \mathrm{s}$ or 0.5/s (Jerger et al., 1987). Another research with four different stimulus rates $(1.1,4.1,7.7$, and $11.3 / \mathrm{s})$ in normal young adults showed that the latency $\mathrm{Pa}$ increased and amplitudes of $\mathrm{Pa}$ and $\mathrm{Pb}$ decreased when the stimulus rates were increased from 1.1/s to 11.3/s (Tucker et al., 2002). It is valuable to note that there is no agreement of the optimal stimulus rates which are very sensitive for the AMLR waves in children and adults although the stimulus rates less than $11 / \mathrm{s}$ is slow enough to produce the AMLR.

The AMLR can be affected by subject parameters such as gender, age, body temperature, state of arousal, and drugs as shown in ABR (Choi et al., 2015). Among these factors, gender is one of the most important factors affecting the latency and amplitude of the AMLR (Amenedo \& Díaz, 1998). Many previous studies have reported an apparent and consistent trend toward longer latencies and smaller amplitudes for males in comparison to females (Stewart et al., 1993). However, there is no agreement of a concrete gender effect on each AMLR wave $(\mathrm{Na}, \mathrm{Pa}, \mathrm{Nb}$, and $\mathrm{Pb})$. In more detail, the latency of the Na component is longer for males than females while the latencies of other components and amplitudes of all AMLR components for male adults were equal to female adults (Amenedo \& Díaz, 1998). The Pb component for elderly patients with Alzheimer's disease was twice as large for females as for males (Phillips et al., 1997). In this study, the average amplitude of the Pa component was $0.83 \mu \mathrm{V}$ for males and $1.35 \mu \mathrm{V}$ for females while that of the $\mathrm{Pb}$ component was $-0.21 \mu \mathrm{V}$ for males and $+0.21 \mu \mathrm{V}$ for females. Absolute amplitude of the $\mathrm{Pb}$ component was equivalent for adult males and females aging from 19 to 78 years old (Rasco et al., 2000). In young male and female adults, there was a significant gender effect on the Pa component and not a significant effect on the $\mathrm{Pb}$ component (Tucker et al., 2002). In more detail, $\mathrm{Pa}$ latencies for males were longer than in females and $\mathrm{Pa}$ amplitudes for females were larger than in males.

We have sought the optimal stimulus rate leading to the robust latency and maximal amplitude of auditory evoked response, particularly ABR waves as well as gender effect (Choi et al., 2015). We expanded our goal to the AMLR waves. Therefore, this study investigated whether the latencies and amplitudes of the AMLR waves are affected by the different stimulus rates and genders in young adults. We attempted to seek the most optimal and stable stimulus rates leading the robust latencies and amplitudes of the AMLR. For this goal, we measured the latencies and amplitudes of the AMLR waves $(\mathrm{Na}, \mathrm{Pa}, \mathrm{Nb}$, and $\mathrm{Pb})$ with five different stimulus rates $(0.5,1,2,4,8 / \mathrm{s})$ in 30 young male and female subjects.

\section{MATERIALS AND METHODS}

\section{Subjects}

The experimental procedures and methods were reviewed and approved by the Bioethic Committee of the Catholic University of Daegu. The experimental processes and procedures are similar to another research previously described with ABR except the use of AMLR (Choi et al., 2015).

Total thirty young adults composed of fifteen males (mean $=25, \mathrm{SD}= \pm 3.7)$ and fifteen females (mean $=21, \mathrm{SD}= \pm 1.4)$ participated in the study. Hearing thresholds of all participants were within normal hearing range (less than $20 \mathrm{~dB} \mathrm{HL}$ ) at frequencies of 250 to $8,000 \mathrm{~Hz}$. The history of all subjects is free of head injury, ear surgery, and audiological or neurological disorders.

\section{Stimuli and ABR recording}

AMLRs were recorded by a GSI Audera system (Grason-Stadler, Eden Prairie, MN, USA). For the AMLR recording, all participants were seated and relaxed in a soft armchair of a sound booth electrically shielded room during the AMLR testing. Before the electrode placement, the skin was cleaned by alcohol pads and the connection between the electrode and skin was enhanced by a conducting gel (NuPrep). For the AMLR recording, active electrodes $(+)$ indicating the non-inverting electrode were placed on the middle of the forehead $(\mathrm{Fz})$ or vertex $(\mathrm{Cz})$ whereas the reference electrodes (-) meaning the inverting electrode were placed 
on the ipsilateral (A1 or A2) and the ground electrode was placed on the low forehead (Fpz). The electrodes were secured with tape. Interelectrode impedances were never exceeded $5 \mathrm{k} \Omega$. Electrical responses were elicited by alternating clicks with 0.1 ms durations. The level of stimuli presentation was $75 \mathrm{~dB}$ normal Hearing Level (nHL) and the stimulus rates were $0.5,1,2,4$, and $8 / \mathrm{s}$. The electrical responses were amplified with 100,000 times and the band-pass filter of 10 to $250 \mathrm{~Hz}$ was used with the sample rate of 400 sweeps, the analysis time of $100 \mathrm{~ms}$, and the test duration of $200 \mathrm{~s}$.

\section{Data analysis}

The latencies and amplitudes of $\mathrm{Na}, \mathrm{Pa}, \mathrm{Nb}$, and $\mathrm{Pb}$ in AMLR were visually identified and obtained from each subject at 5 different stimulus rate conditions $(0.5,1,2,4$, and $8 / \mathrm{s})$. The latency and amplitude data were compared and analyzed in five different stimulus rate conditions and two different gender groups (male and female). Three independent observers for high reliability confirmed the latencies and amplitudes of all AMLR data. All graphic presentations in the study were made in SigmaPlot (version 9; Systat Software, San Jose, CA, USA) and shown in a mean \pm S.E.M.

\section{Statistical analysis}

Statistical differences in the latencies and amplitudes of $\mathrm{Na}$, $\mathrm{Pa}, \mathrm{Nb}$, and $\mathrm{Pb}$ among the different experimental groups were also compared using one-way ANOVA (IBM SPSS 19.0; IBM corp., Armonk, NY, USA). The Fisher's least squares difference post hoc test was then used to evaluate the statistical differences of specific pairs of values. A statistical significant difference was determined by $p<0.05, p<0.01$, and $p<0.001$, respectively.

\section{RESULTS}

We evaluated statistical differences in the latencies and am- plitudes of $\mathrm{Na}, \mathrm{Pa}, \mathrm{Nb}$, and $\mathrm{Pb}$ in AMLR waves according to stimulus rate and gender. Table 1 shows the descriptive statistics of latencies and amplitudes of $\mathrm{Na}, \mathrm{Pa}, \mathrm{Nb}$, and $\mathrm{Pb}$ as a function of stimulus rate $(0.5,1,2,4$, and $8 / \mathrm{s})$.

Figure 1 shows the latencies of $\mathrm{Na}, \mathrm{Pa}, \mathrm{Nb}$, and $\mathrm{Pb}$ as a function of five different stimulus rate conditions. When the stimulus rate increased from $0.25 / \mathrm{s}$ to $8 / \mathrm{s}$, the latencies of $\mathrm{Na}, \mathrm{Pa}$, and $\mathrm{Nb}$ were unchanged. However, the latency of $\mathrm{Pb}$ increased from $46 \mathrm{~ms}$ to about $56 \mathrm{~ms}$ although there was no significant difference. The one-way ANOVA showed that there was significant difference among the five different stimulus rates for the latencies of $\mathrm{Na}[\mathrm{F}(4,295)=3.255, p<0.05]$.

Further analysis for within-subjects contrasts was performed to identify significant differences among five different stimulus rates in latencies of each AMLR wave.

As shown in Table 2, the latency of Na showed significant differences at the stimulus rates of $2 / \mathrm{s}$ and $8 / \mathrm{s}$, respectively, in comparison with the stimulus rate of $0.5 / \mathrm{s}$. Furthermore, significant differences were observed in the latency of $\mathrm{Na}$ at the stimulus rates of $2 / \mathrm{s}$ and $4 / \mathrm{s}$ in comparison with the stimulus of

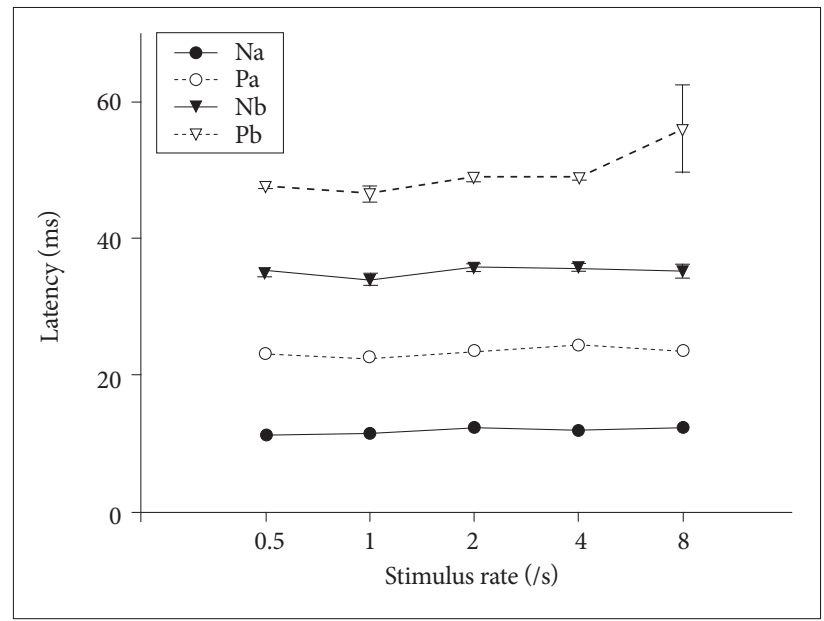

Figure 1. The latencies of $\mathrm{Na}, \mathrm{Pa}, \mathrm{Nb}$, and $\mathrm{Pb}$ as a function of five different stimulus rates.

Table 1. Means and standard deviations for the latencies and amplitudes of $\mathrm{Na}, \mathrm{Pa}, \mathrm{Nb}$, and $\mathrm{Pb}$ in five different stimulus rates

\begin{tabular}{|c|c|c|c|c|c|c|c|}
\hline \multirow{2}{*}{ Component } & \multirow{2}{*}{ Measurement } & \multicolumn{5}{|c|}{ Rate } & \multirow{2}{*}{$p$-value } \\
\hline & & 0.5 & 1 & 2 & 4 & 8 & \\
\hline \multirow[t]{2}{*}{$\mathrm{Na}$} & Latency & $11.32 \pm 1.68$ & $11.56 \pm 2.90$ & $12.38 \pm 1.65$ & $11.97 \pm 1.66$ & $12.37 \pm 2.07$ & $0.012^{*}$ \\
\hline & Amplitude & $-0.61 \pm 0.64$ & $-0.58 \pm 0.49$ & $-0.60 \pm 0.42$ & $-0.51 \pm 0.39$ & $-0.63 \pm 0.55$ & 0.781 \\
\hline \multirow[t]{2}{*}{$\mathrm{Pa}$} & Latency & $23.24 \pm 3.03$ & $22.74 \pm 4.79$ & $23.97 \pm 3.09$ & $24.39 \pm 3.35$ & $23.63 \pm 2.75$ & 0.090 \\
\hline & Amplitude & $1.05 \pm 0.71$ & $0.79 \pm 0.54$ & $0.69 \pm 0.51$ & $0.78 \pm 0.55$ & $0.83 \pm 0.69$ & $0.025^{*}$ \\
\hline \multirow[t]{2}{*}{$\mathrm{Nb}$} & Latency & $35.06 \pm 6.89$ & $34.04 \pm 9.53$ & $35.81 \pm 7.24$ & $35.56 \pm 7.22$ & $35.42 \pm 10.23$ & 0.800 \\
\hline & Amplitude & $-0.78 \pm 0.69$ & $-0.65 \pm 0.94$ & $-0.51 \pm 0.38$ & $-0.42 \pm 0.46$ & $-0.52 \pm 0.43$ & $0.019^{*}$ \\
\hline \multirow[t]{2}{*}{$\mathrm{Pb}$} & Latency & $47.72 \pm 3.94$ & $46.66 \pm 10.02$ & $48.87 \pm 4.97$ & $48.93 \pm 4.34$ & $56.02 \pm 50.03$ & 0.193 \\
\hline & Amplitude & $0.48 \pm 0.46$ & $0.65 \pm 0.36$ & $0.50 \pm 0.34$ & $0.53 \pm 0.40$ & $0.50 \pm 0.44$ & 0.127 \\
\hline
\end{tabular}

${ }^{*} p<0.05$ 
$1 /$ s. In the latency of $\mathrm{Pa}$, significant difference was only shown between the stimulus rates of $1 / \mathrm{s}$ and $8 / \mathrm{s}$. No significant differences in the latency of $\mathrm{Nb}$ were found any stimulus rates. Finally, significant differences in the latency of $\mathrm{Pb}$ were shown in the stimulus rates of $8 / \mathrm{s}$ and $1 / \mathrm{s}$ in comparison with the stimulus rate of $0.5 / \mathrm{s}$.

Additionally, one-way ANOVA showed whether there were significant differences in the amplitudes of $\mathrm{Na}, \mathrm{Pa}, \mathrm{Nb}$, and $\mathrm{Pb}$ among the five different stimulus rates as shown in Table 1. Ta-

Table 2. Multiple comparisons of the latencies of $\mathrm{Na}, \mathrm{Pa}, \mathrm{Nb}$, and $\mathrm{Pb}$ among five different stimulus rates

\begin{tabular}{crccc}
\hline Component & Rate & $p$-value & Rate & $p$-value \\
\hline $\mathrm{Na}$ & $0.5-1$ & 0.526 & $1-4$ & 0.274 \\
& $0.5-2$ & $0.005^{\dagger}$ & $1-8$ & $0.030^{*}$ \\
& $0.5-4$ & 0.084 & $2-4$ & 0.270 \\
& $0.5-8$ & $0.005^{\dagger}$ & $2-8$ & 0.975 \\
$\mathrm{~Pa}$ & $1-2$ & $0.028^{*}$ & $4-8$ & 0.281 \\
& $0.5-1$ & 0.434 & $1-4$ & $0.010^{\dagger}$ \\
& $0.5-2$ & 0.250 & $1-8$ & 0.162 \\
& $0.5-4$ & 0.070 & $2-4$ & 0.506 \\
$\mathrm{Nb}$ & $0.5-8$ & 0.536 & $2-8$ & 0.595 \\
& $1-2$ & 0.054 & $4-8$ & 0.232 \\
& $0.5-1$ & 0.505 & $1-4$ & 0.319 \\
& $0.5-2$ & 0.623 & $1-8$ & 0.366 \\
$\mathrm{~Pb}$ & $0.5-4$ & 0.742 & $2-4$ & 0.871 \\
& $0.5-8$ & 0.812 & $2-8$ & 0.800 \\
& $1-2$ & 0.247 & $4-8$ & 0.927 \\
& $0.5-1$ & 0.802 & $1-4$ & 0.591 \\
& $0.5-2$ & 0.785 & $1-8$ & $0.027^{*}$ \\
& $0.5-4$ & 0.775 & $2-4$ & 0.989 \\
& $0.5-8$ & $0.050^{*}$ & $2-8$ & 0.091 \\
& $1-2$ & 0.601 & $4-8$ & 0.093 \\
\hline & & & &
\end{tabular}

${ }^{*} p<0.05,{ }^{\dagger} p<0.01$

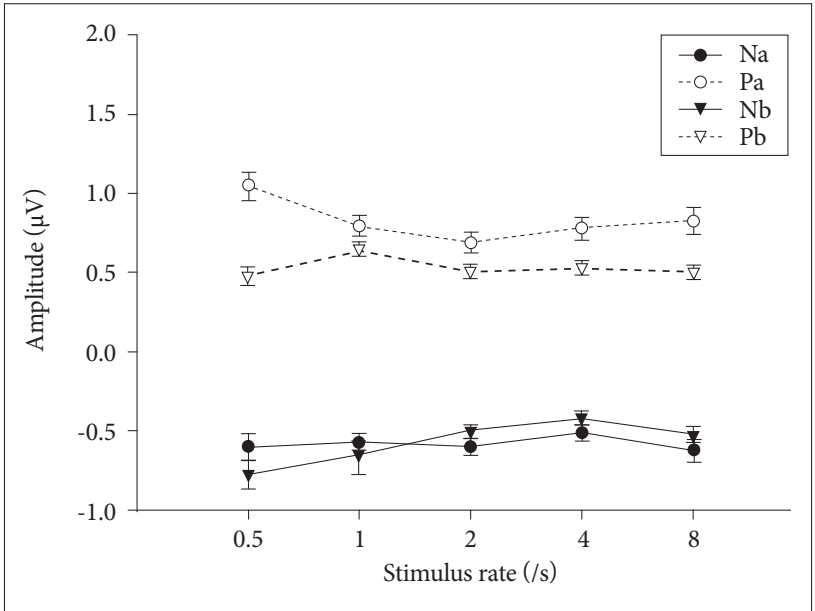

Figure 2. The amplitudes of $\mathrm{Na}, \mathrm{Pa}, \mathrm{Nb}$, and $\mathrm{Pb}$ as a function of five different stimulus rate conditions. ble 1 and Figure 2 present the amplitudes of $\mathrm{Na}, \mathrm{Pa}, \mathrm{Nb}$, and $\mathrm{Pb}$ according to five different stimulus rate conditions. Significant differences were observed in the amplitudes of $\mathrm{Pa}$ and $\mathrm{Nb}$ in different stimulus rates $[\mathrm{F}(4,295)=2.84, p<0.05, \mathrm{~F}(4,295)=$ $3.01, p<0.05$ ]. When the stimulus rate increased from $0.5 / \mathrm{s}$ to $8 / \mathrm{s}$, the amplitudes of $\mathrm{Na}$ and $\mathrm{Nb}$ increased a little but the amplitudes of $\mathrm{Pa}$ and $\mathrm{Pb}$ decreased slowly. The amplitudes of $\mathrm{Na}$ and $\mathrm{Nb}$ were the largest at the stimulus rate of $4 / \mathrm{s}$. The amplitudes of $\mathrm{Pa}$ and $\mathrm{Pb}$ were the largest at the stimulus rates of $0.5 \mathrm{~s}$ and $1 / \mathrm{s}$ while the smallest at the stimulus rate of $2 / \mathrm{s}$.

Furthermore, multiple comparisons were performed to investigate the significant differences in the amplitudes of $\mathrm{Na}, \mathrm{Pa}$, $\mathrm{Nb}$, and $\mathrm{Pb}$ among the five different stimulus rates as shown in Table 3.

For the amplitude of $\mathrm{Na}$, no significant differences were observed among any stimulus rate of $0.5,1,2,4$, and $8 / \mathrm{s}$. For the amplitude of $\mathrm{Pa}$, significant differences were observed in the stimulus rates of $1,2,4$ and $8 / \mathrm{s}$ in comparison with the stimulus rate of $0.5 / \mathrm{s}$. For the amplitude of $\mathrm{Nb}$, significant differences were observed in the stimulus rate of 2,4 , and $8 / \mathrm{s}$ in comparison with that of $0.5 / \mathrm{s}$ and between the stimulus rates of 1 and $4 /$ s. For the amplitude of $\mathrm{Pb}$, significant differences were observed in the stimulus rate of $0.5,2$, and $8 / \mathrm{s}$ in comparison with that of $1 / \mathrm{s}$.

Table 3. Multiple comparisons of the amplitudes of $\mathrm{Na}, \mathrm{Pa}, \mathrm{Nb}$, and $\mathrm{Pb}$ among five different levels of stimulus rates

\begin{tabular}{ccccc}
\hline Component & Rate & $p$-value & Rate & $p$-value \\
\hline $\mathrm{Na}$ & $0.5-1$ & 0.770 & $1-4$ & 0.489 \\
& $0.5-2$ & 0.959 & $1-8$ & 0.595 \\
& $0.5-4$ & 0.326 & $2-4$ & 0.352 \\
& $0.5-8$ & 0.811 & $2-8$ & 0.771 \\
$\mathrm{~Pa}$ & $1-2$ & 0.810 & $4-8$ & 0.222 \\
& $0.5-1$ & $0.023^{*}$ & $1-4$ & 0.882 \\
& $0.5-2$ & $0.002^{\dagger}$ & $1-8$ & 0.777 \\
& $0.5-4$ & $0.016^{*}$ & $2-4$ & 0.451 \\
$\mathrm{Nb}$ & $0.5-8$ & $0.046^{*}$ & $2-8$ & 0.236 \\
& $1-2$ & 0.367 & $4-8$ & 0.665 \\
& $0.5-1$ & 0.275 & $1-4$ & $0.044^{*}$ \\
& $0.5-2$ & $0.018^{*}$ & $1-8$ & 0.250 \\
& $0.5-4$ & $0.002^{\dagger}$ & $2-4$ & 0.462 \\
$\mathrm{~Pb}$ & $0.5-8$ & $0.025^{*}$ & $2-8$ & 0.889 \\
& $1-2$ & 0.198 & $4-8$ & 0.382 \\
& $0.5-1$ & $0.017^{*}$ & $1-4$ & 0.091 \\
& $0.5-2$ & 0.694 & $1-8$ & $0.037^{*}$ \\
& $0.5-4$ & 0.478 & $2-4$ & 0.751 \\
& $0.5-8$ & 0.757 & $2-8$ & 0.933 \\
& $1-2$ & $0.045^{*}$ & $4-8$ & 0.688 \\
\hline \multirow{3}{*}{$0.05, p<0.01$} & & &
\end{tabular}

${ }^{*} p<0.05,{ }^{\dagger} p<0.01$ 
We also investigated the gender effect on the latencies and amplitudes of each AMLR wave. Table 4 shows the descriptive statistics of latencies and amplitudes of $\mathrm{Na}, \mathrm{Pa}, \mathrm{Nb}$, and $\mathrm{Pb}$ according to gender (female and male).

Figures 3 and 4 present the latencies and amplitudes of $\mathrm{Na}, \mathrm{Pa}$, $\mathrm{Nb}$, and $\mathrm{Pb}$ according to different gender groups. For the latencies of $\mathrm{Pa}$, there were significant differences in different gender groups $[\mathrm{F}(1,298)=21.74, p<0.001]$. For the latencies of other AMLR waves, there were no significant differences between different gender groups. For the latencies of all AMLR waves, the female group was higher than the male groups. The difference was the largest in the latency of $\mathrm{Pa}$. However, the amplitudes of all AMLR waves $(\mathrm{Na}, \mathrm{Pa}, \mathrm{Nb}$, and $\mathrm{Pb}$ ) were significantly higher in the male group than the female group $[F(1,298)=$ $12.79, p<0.001, \mathrm{~F}(1,298)=14.99, p<0.001, \mathrm{~F}(1,298)=6.68, p<$ $0.05, \mathrm{~F}(1,298)=11.02, p<0.01]$. The amplitudes of Na were similar to those of $\mathrm{Nb}$ at the same gender. The amplitude of $\mathrm{Pa}$ was the largest in comparison with those of other AMLR waves.

Table 4. Means and standard deviations for the latencies and amplitudes of AMLR in two gender groups

\begin{tabular}{|c|c|c|c|c|}
\hline \multirow{2}{*}{ Component } & \multirow{2}{*}{ Measurement } & \multicolumn{2}{|c|}{ Gender } & \multirow{2}{*}{$\begin{array}{c}p^{-} \\
\text {value }\end{array}$} \\
\hline & & Female & Male & \\
\hline \multirow[t]{2}{*}{$\mathrm{Na}$} & Latency & $11.95 \pm 2.09$ & $11.89 \pm 2.07$ & 0.787 \\
\hline & Amplitude & $-0.69 \pm 0.56$ & $-0.48 \pm 0.42$ & $0.000^{\dagger}$ \\
\hline \multirow[t]{2}{*}{$\mathrm{Pa}$} & Latency & $24.50 \pm 3.38$ & $22.68 \pm 3.40$ & $0.000^{\dagger}$ \\
\hline & Amplitude & $0.69 \pm 0.60$ & $0.96 \pm 0.60$ & $0.000^{\dagger}$ \\
\hline \multirow[t]{2}{*}{$\mathrm{Nb}$} & Latency & $35.85 \pm 10.42$ & $34.50 \pm 5.38$ & 0.160 \\
\hline & Amplitude & $-0.67 \pm 0.74$ & $-0.48 \pm 0.47$ & $0.010^{*}$ \\
\hline \multirow[t]{2}{*}{$\mathrm{Pb}$} & Latency & $50.32 \pm 4.39$ & $48.96 \pm 32.49$ & 0.610 \\
\hline & Amplitude & $0.46 \pm 0.43$ & $0.61 \pm 0.36$ & $0.001^{*}$ \\
\hline
\end{tabular}

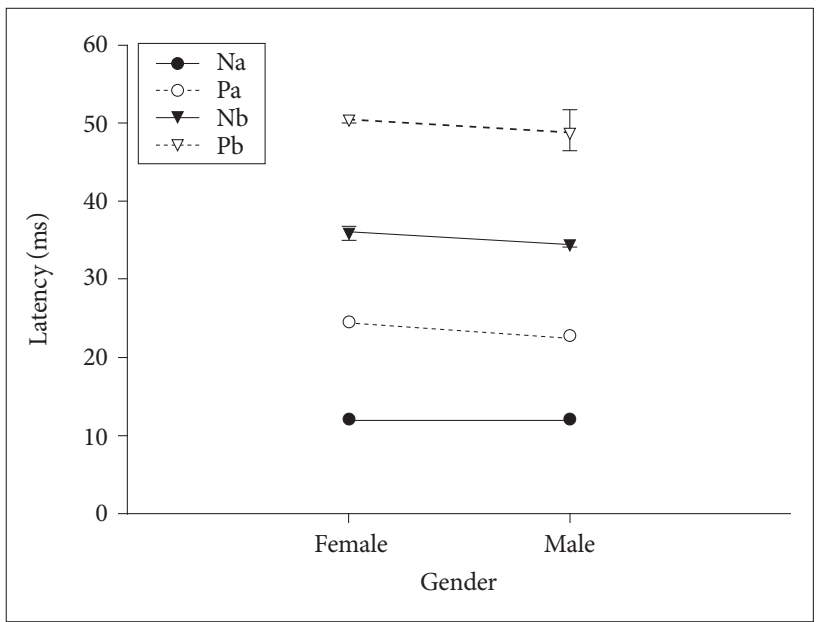

Figure 3. The latencies of $\mathrm{Na}, \mathrm{Pa}, \mathrm{Nb}$, and $\mathrm{Pb}$ in different gender groups.

\section{DISCUSSIONS}

The purpose of this study was to investigate the effects of stimulus rates and gender on the latencies and amplitudes of the AMLR waves $(\mathrm{Na}, \mathrm{Pa}, \mathrm{Nb}$, and $\mathrm{Pb}$ ) in Korean young adults with normal hearing. The results of this study showed that there were significant differences in the $\mathrm{Na}$ latency and the $\mathrm{Pa}$ and $\mathrm{Nb}$ amplitudes with increasing the stimulus rate. The $\mathrm{Na}$ latency slightly increased with faster stimulus rates. The $\mathrm{Pa}$ amplitude decreased with faster stimulus rates while the $\mathrm{Nb}$ amplitude increased with increasing stimulus rates. This finding is inconsistent with the findings of other previous studies showed the that $\mathrm{Pa}$ latency significantly increased and the $\mathrm{Pa}$ and $\mathrm{Pb}$ amplitudes decreased with faster stimulus rates (Dietrich et al., 1995; McFarland et al., 1975; Nelson et al., 1997; Picton et al., 1974; Tucker et al., 2002). However, the Pb amplitudes showed a significant decrease in Alzheimer's disease (Buchwald et al., 1989), multiple sclerosis (Hendler et al., 1990), and stuttering males (Dietrich et al., 1995). The discrepancy may result from the differences in stimulus rates, subject types, and age used in each study. More research is needed to determine the effects of stimulus rates on the AMLR waveforms in different subjects.

On the other hand, this study investigated the effect of gender on the latency and amplitude of the AMLR waveforms such as $\mathrm{Na}, \mathrm{Pa}, \mathrm{Nb}$, and $\mathrm{Pb}$. The results showed that the latencies of all AMLR waveforms in females were longer than in males but the amplitudes of all AMLR waveforms in males were larger than in females. This finding is consistent with the finding of Amenedo \& Díaz (1998) that the latency of $\mathrm{Na}$ was longer in females than males. However, the results of this study are in-

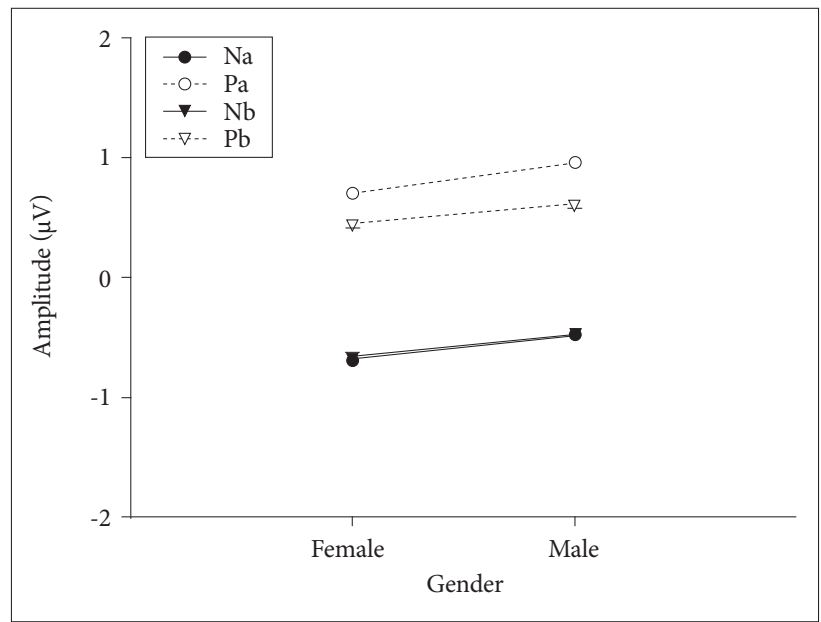

Figure 4. The amplitudes of $\mathrm{Na}, \mathrm{Pa}, \mathrm{Nb}$, and $\mathrm{Pb}$ in different gender groups. 
consistent with many previous studies reported that there is a clear trend toward longer latencies and smaller amplitudes of the AMLR waves in females in comparison to males (Clementz et al., 1998; Rodríguez-Holguín et al., 2001; Tucker et al., 2002). This disagreement may result from the differences in sampling size, stimulus rate, intensity levels, subject age, skull size, and height size in each research. More investigation is needed to determine the effects of gender on the latency and amplitude of the AMLR waveforms in different subjects.

The effects of stimulus rate and gender on the AMLR waveforms investigated by our present study can be affected by age. The average ages used in our study were about 25 years old for males and 21 years old for females. Many previous studies have reported age-related changes in the AMLR waveforms such as poorer waveform morphology, increased latency, and increased amplitude (Amenedo \& Díaz, 1998; McGee \& Kraus, 1996; Woods \& Clayworth, 1986). These changes include a slight increase or no increase in the latencies of $\mathrm{Na}, \mathrm{Pa}$, and $\mathrm{Pb}$ with age and a linear increase in the amplitudes of $\mathrm{Pa}$ and $\mathrm{Pb}$ with age. In more detail, the amplitude of $\mathrm{Pb}$ increased with age in women (Pfefferbaum et al., 1979). The Pb latency was longer in older women (Erwin \& Buchwald, 1986). Slower stimulus rate (1 to $2 /$ s) has been used to obtain a true AMLR waveform in neonates and young children and the Pa components of the AMLR were not reliably recorded for stimulus rates exceeding $5 / \mathrm{s}$ (Jerger et al., 1987). In pathology, slow stimulus rate of $1 / \mathrm{s}$ is required to consistently record the $\mathrm{Pb}$ components of the AMLR (Buchwald et al., 1989; Hall, 2007). Furthermore, in individuals with Alzheimer's disease, the latency and amplitude of Pa was normal but the amplitude of $\mathrm{Pb}$ significantly decreased (Buchwald et al., 1989). In patients with Alzheimer's disease, the latency of $\mathrm{Pb}$ was longer and the amplitude of the $\mathrm{Pb}$ was larger than in age-matched controls (Irimajiri et al., 2005). In patients with Parkinson's disease, there was a $\mathrm{Pb}$ abnormality (Pekkonen et al., 1998). Therefore, the larger amplitudes of all AMLR waveforms in males shown in this study may come from the difference in the average age of the subjects participated in the study. More investigation is needed to consider advancing age for future study investigating the effects of stimulus rates and gender on the AMLR waveforms in relation to the effects of age.

We investigated the optimal stimulus rates characterizing the latency and amplitude of the AMLR waveforms in different gender. In this study, it is valuable to note that there are some limitation on generalization and clinical application due to the small size of subjects, the selected subjects in the specific locations, the limited ranges of stimulus rate, and the different stim- ulus conditions as shown in our previous study of ABR (Choi et al., 2015). Nevertheless, this study provides gender-specific norms for male and female subjects for the AMLR waveforms. These norms will be usefully applied to individuals with aging related hearing loss, noise induced hearing loss, and different hearing loss.

In conclusion, this research investigated the effect of stimulus rate and gender on the latency and amplitude of the AMLR waveforms in young adults. Significant differences in the latency and amplitude of $\mathrm{Na}, \mathrm{Pa}, \mathrm{Nb}$, and $\mathrm{Pb}$ were investigated with the stimulus rates of $0.5,1,2,4$, and $8 / \mathrm{s}$ in female and male subjects. Stimulus rates showed a significant effect on the $\mathrm{Na}$ latency, $\mathrm{Pa}$ amplitude, and $\mathrm{Nb}$ amplitude. The $\mathrm{Na}$ latency slightly increased with faster stimulus rates. The $\mathrm{Pa}$ amplitude decreased with increasing stimulus rates while the $\mathrm{Nb}$ amplitude slightly increased with faster stimulus rates. Significant differences in gender were observed on the latency of $\mathrm{Na}$ and the amplitudes of all AMLR waveforms. The latencies of $\mathrm{Na}, \mathrm{Pa}, \mathrm{Nb}$, and $\mathrm{Pb}$ in females were longer than in males while the amplitudes of $\mathrm{Na}, \mathrm{Pa}, \mathrm{Nb}$, and $\mathrm{Pb}$ in males are larger than in females. This provides useful information of gender-specific norms on the latency and amplitude of the AMLR waveform and clinical insight of the optimal stimulus rates to elicit the apparent AMLR waveform.

\section{Acknowledgments}

This study was supported by a research grant of Catholic University of Daegu.

\section{REFERENCES}

Amenedo, E. \& Díaz, F. (1998). Effects of aging on middle-latency auditory evoked potentials: A cross-sectional study. Biological Psychiatry, 43(3), 210-219.

Buchwald, J. S., Erwin, R. J., Read, S., Van Lancker, D., \& Cummings, J. L. (1989). Midlatency auditory evoked responses: Differential abnormality of P1 in Alzheimer's disease. Electroencephalography and Clinical Neurophysiology/Evoked Potentials Section, 74(5), 378-384.

Choi, C-H., Jang K-H., \& Choi, S. H. (2015). Effect of stimulus rate and gender on auditory brainstem response in Korean young adults. Audiology, 11(2), 140-155.

Clementz, B. A., Geyer, M. A., \& Braff, D. L. (1998). Poor P50 suppression among schizophrenia patients and their first-degree biological relatives. American Journal of Psychiatry, 155(12), 1691-1694.

Dietrich, S., Barry, S. J., \& Parker, D. E. (1995). Middle latency auditory responses in males who stutter. Journal of Speech, Language, and Hearing Research, 38(1), 5-17.

Erwin, R. J. \& Buchwald, J. S. (1986). Midlatency auditory evoked responses: Differential recovery cycle characteristics. Electroencephalography and Clinical Neurophysiology, 64(5), 417-423.

Hall, J. W. (2007). New Handbook of Auditory Evoked Responses. (pp. 441487.). Boston, MA: Allyn and Bacon.

Hendler, T., Squires, N. K., \& Emmerich, D. S. (1990). Psychophysical measures of central auditory dysfunction in multiple sclerosis: Neuro- 
physiological and neuroanatomical correlates. Ear and Hearing, 11(6), 403-416.

Irimajiri, R., Golob, E. J., \& Starr, A. (2005). Auditory brain-stem, middleand long-latency evoked potentials in mild cognitive impairment. Clinical Neurophysiology, 116(8), 1918-1929.

Jerger, J., Chmiel, R., Glazeb, D., \& Frost, J. D. (1987). Rate and filter dependence of the middle-latency response in infants. Audiology, 26(5), 269-283.

Liegeois-Chauvel, C., Musolino, A., Badier, J. M., Marquis, P., \& Chauvel, P. (1994). Evoked potentials recorded from the auditory cortex in man: Evaluation and topography of the middle latency components. Electroencephalography and Clinical Neurophysiology/Evoked Potentials Section, 92(3), 204-214.

McFarland, W. H., Vivion, M. C., Wolf, K. E., \& Goldstein, R. (1975). Reexamination of effects of stimulus rate and number on the middle components of the averaged electroencephalic response. Audiology, 14(5-6), 456-465.

McGee, T. \& Kraus, N. (1996). Auditory development reflected by middle latency response. Ear and Hearing, 17(5), 419-429.

McGee, T., Kraus, N., Comperatore, C., \& Nicol, T. (1991). Subcortical and cortical components of the MLR generating system. Brain Research, 544(2), 211-220.

Nelson, M. D., Hall, J. W., \& Jacobson, G. P. (1997). Factors affecting the recordability of auditory evoked response component $\mathrm{Pb}(\mathrm{P} 1)$. Journal of the American Academy of Audiology, 8(2), 89-99.

Pekkonen, E., Ahveninen, J., Virtanen, J., \& Teräväinen, H. (1998). Parkinson's disease selectively impairs preattentive auditory processing: An MEG study. Neuroreport, 9(13), 2949-2952.

Pfefferbaum, A., Horvath, T. B., Roth, W. T., \& Kopell, B. S. (1979). Eventrelated potential changes in chronic alcoholics. Electroencephalogra- phy and Clinical Neurophysiology, 47(6), 637-647.

Phillips, N. A., Connolly, J. F., Mate-Kole, C. C., \& Gray, J. (1997). Individual differences in auditory middle latency responses in elderly adults and patients with Alzheimer's disease. International Journal of Psychophysiology, 27(2), 125-136.

Picton, T. W., Hillyard, S. A., Krausz, H. I., \& Galambos, R. (1974). Human auditory evoked potentials. I: Evaluation of components. Electroencephalography and Clinical Neurophysiology, 36, 179-190.

Polyakov, A. \& Pratt, H. (1994). Three-channel Lissajous' trajectory of human middle latency auditory evoked potentials. Ear and Hearing, 15(5), 390-399.

Purdy, S. C. \& Kelly, A. S. (2016). Change in speech perception and auditory evoked potentials over time after unilateral cochlear implantation in postlingually deaf adults. Seminars in Hearing, 37(1), 62-73.

Rasco, L., Skinner, R. D., \& Garcia-Rill, E. (2000). Effect of age on sensory gating of the sleep state-dependent P1/P50 midlatency auditory evoked potential. Sleep Research Online, 3(3), 97-105.

Rodríguez Holguín, S., Corral, M., \& Cadaveira, F. (2001). Middle-latency auditory evoked potentials in children at high risk for alcoholism. Neurophysiologie Clinique, 31(1), 40-47.

Stewart, M. G., Jerger, J., \& Lew, H. L. (1993). Effect of handedness on the middle latency auditory evoked potential. Otology and Neurotology, 14(6), 595-600.

Tucker, D. A., Dietrich, S., Harris, S., \& Pelletier, S. (2002). Effects of stimulus rate and gender on the auditory middle latency response. Journal of the American Academy of Audiology, 13(3), 146-153.

Woods, D. L. \& Clayworth, C. C. (1986). Age-related changes in human middle latency auditory evoked potentials. Electroencephalography and Clinical Neurophysiology/Evoked Potentials Section, 65(4), 297-303. 